\title{
pro.posıções
}

$e$-ISSN 1980-6248

http://dx.doi.org/10.1590/1980-6248-2017-0089

ARTIGOS

\section{O destino social de licenciandos e bacharéis em Química: um estudo de caso sobre a formação de professores no plano microssociológico ${ }^{2}$}

\section{The social destination of chemistry teacher education and other graduates: a case study on the pre-service teacher education at the micro-sociological level}

Luciana Massi (i)

Alberto Villani (ii)

(i) Universidade Estadual Paulista Júlio de Mesquita Filho - UNESP, Araraquara, SP, Brasil. https://orcid.org/0000-0001-8761-3181, luciana.massi@unesp.br.

(ii) Universidade de São Paulo - USP, São Paulo, SP, Brasil. https://orcid.org/0000-0003-2760-240X, avillani@usp.br.

Resumo:
A “teoria da reprodução", enunciada por Bourdieu na década de 1960, sustentava
que as classes menos favorecidas tinham acesso a oportunidades de menor prestígio
no sistema escolar. No Brasil, desde então o sistema educacional sofreu uma grande
ampliação qualitativa e quantitativa, gerando hierarquias de acordo com as classes
sociais, inclusive entre modalidades de um mesmo curso de graduação. Neste
trabalho, apresentaremos um caso que diverge dessa tradição no plano
microssociológico em uma graduação em Química oferecida nas modalidades
licenciatura e bacharelado. A partir de dados quantitativos, qualitativos e
longitudinais, observamos que os licenciandos são originários de classes sociais
menos favorecidas, mas concluem o curso com as mesmas oportunidades de
inserção profissional e acadêmica que os bacharéis, de forma a alterar seu destino
social mais provável.
Palavras-chave: ensino superior, sociologia da educação, Pierre Bourdieu,
licenciatura

\footnotetext{
${ }^{1}$ Apoio: Coordenação de Aperfeiçoamento de Pessoal de Nível Superior (Capes).

${ }^{2}$ Normalização, preparação e revisão textual: Douglas Mattos (Tikinet) - revisao@tikinet.com.br
} 


\title{
pro.posıções
}

http://dx.doi.org/10.1590/1980-6248-2017-0089

\begin{abstract}
:
The "social reproduction", posited by Bourdieu in the 1960s showed that low income class had access to less prestigious opportunities in the school system. Since then, in Brazil, the system has undergone a major qualitative and quantitative expansion that generated hierarchies, according to social classes, even between forms of the same course degree. In this paper we present a case that diverge from this tradition: a Chemistry undergraduate degree offered in the modalities of teacher and professional education. From quantitative, qualitative and longitudinal data we observed that undergraduate teacher education students come from lower social classes, but conclude the course with the same opportunities for professional and academic integration that professional education, altering its likely social destination.
\end{abstract}

Keywords: higher education, sociology of education, Pierre Bourdieu, teacher education

Os estudos de Pierre Bourdieu e Jean-Claude Passeron (2012, 2014) publicados em Os herdeiros, de 1964, e $A$ reprodução, de 1970, mostraram, a partir de análises estatísticas, a diferença de oportunidades (ou probabilidade objetiva) de acesso à escola para jovens de diferentes camadas sociais, concluindo que os menos favorecidos socialmente tinham menos chances de ascensão social pela escola. Assim, ao invés de promover justiça e igualdade, como pensava-se na década de 1960, a escola reproduzia e legitimava as desigualdades sociais (Nogueira \& Nogueira, 2002). No Brasil, a inserção dessas obras foi caracterizada por uma leitura parcial, com foco na dicotomia "reprodução vs. transformação", constatando a dimensão reprodutivista da escola (Catani, Catani, \& Pereira, 2001) e associando os autores à chamada "sociologia da reprodução".

O quadro pessimista enunciado por Bourdieu e Passeron sobre o sistema francês, que se repetia em outros países, sofreu várias alterações até os dias atuais. Passadas quatro décadas dessa publicação, é inegável que o acesso à escola e ao ensino superior tenha aumentado consideravelmente. Porém, fica nítido que surgiram outras formas de perpetuar a exclusão dos menos favorecidos no sistema escolar. Duru-Bellat (2006) aponta a inflação dos diplomas na atualidade, que levou o sistema escolar a diferenciações qualitativas que promovem uma “democratização segregativa”. Ou seja, aceder ao ensino superior público ou privado, a cursos de maior ou menor prestígio e a modalidades diferentes dentro do mesmo curso (como 


\section{pro.posıções}

http://dx.doi.org/10.1590/1980-6248-2017-0089

\section{$e-I S S N$ 1980-6248}

bacharelado ou licenciatura) são opções que carregam diferenças em termos de probabilidade de acesso, qualidade de ensino e oportunidade de inserção no mercado de trabalho.

O profissional bacharel, por exemplo, em geral é mais reconhecido e valorizado do que o licenciado, diretamente associado com a carreira docente, muito desprestigiada em nosso país. Segundo Dias-da-Silva e Muzzeti (2006), essa diferenciação pode ser explicada pela análise do campo universitário e pelo estabelecimento de graus de excelência, nos quais o bacharel ocupa o lugar de autoridade científica. De fato, a criação de cursos de licenciatura (LIC) constitui "um ônus para os cientistas consolidarem seus projetos de formação dos bacharéis" e, muitas vezes, é relegada a faculdades particulares (Dias-da-Silva \& Muzzeti, 2006, p. 14). Para as autoras, os cursos de LIC em universidades públicas seriam "apêndices" dos cursos de bacharelado (BAC) e tarefa "pouco nobre" ou "pouco legítima", portanto, "relegada aos docentes da área de educação, considerados menos providos de capital político e social” (p. 16).

O desprestígio acadêmico e social da LIC contribui para que essa modalidade tenha índices de evasão maiores do que os BAC das mesmas áreas. Na Química, estima-se uma evasão nacional aproximada de 30\% no BAC contra 70\% na LIC (Zucco, 2007). Contrariando todas essas tendências, neste trabalho apresentaremos nossa argumentação de que o curso de LIC em Química do Instituto de Química (IQ) da Universidade Estadual Paulista (Unesp) de Araraquara representa um contraexemplo do destino social mais provável dos licenciandos. Enquanto a "teoria da reprodução" é ampla e se refere ao "sistema das relações entre o sistema de ensino e a estrutura das relações entre as classes" (Bourdieu \& Passeron, 2014, p. 16), no plano microssociológico, Nogueira e Nogueira (2002) destacam que "existem diferenças significativas no modo como cada escola e/ou professor participa desse processo de reprodução social" e que elas "foram, em grande medida, negligenciadas por Bourdieu" (p. 34). Assim, partindo desse plano, estabelecemos uma relação problematizadora com a "teoria da reprodução" para analisar a modificação identificada nesse curso de LIC.

Nossa pesquisa partiu da constatação de índices de evasão baixíssimos na LIC, inferiores aos do BAC: 15\% contra 25\%. Construiremos nossa argumentação apresentando, inicialmente, as condições encontradas na graduação, a partir da história de criação e das características do curso de LIC; em seguida, mostraremos que os alunos do curso de LIC têm um perfil socioeconômico menos favorecido do que os alunos do BAC. No entanto, esse conjunto de fatores, de fato, fornece aos licenciandos a possibilidade de uma formação em Química 


\section{pro.posições}

http://dx.doi.org/10.1590/1980-6248-2017-0089

$e$-ISSN 1980-6248

equivalente ao bacharel e um acréscimo exclusivo de formação humana, que permite ao licenciado uma modificação do que tendencialmente seria seu destino mais provável: uma inserção profissional menos prestigiada e legítima do que a do bacharel. Discutiremos, ainda, a implicação desse cenário para a formação de professores.

\section{Metodologia de coleta e análise de dados}

Seguindo os preceitos metodológicos do estudo de caso, nosso estudo se baseia em dados obtidos através de diferentes fontes. Segundo Yin (1989), "a força única do estudo de caso é a sua capacidade de lidar com uma completa variedade de evidências - documentos, artefatos, entrevistas e observações” (p. 20, tradução nossa). Para reconstruir a história da instituição e determinar as características do curso e das atividades de pesquisa e extensão, realizamos entrevistas extensivas com docentes, funcionários e alunos do curso de graduação. Neste trabalho, privilegiamos as entrevistas semidiretivas, conduzidas com oito docentes que participaram dos primeiros momentos de desenvolvimento do curso, seis docentes participantes do momento atual da instituição e uma funcionária da Diretoria Técnica Acadêmica com importante atuação na instituição. Também utilizamos entrevistas realizadas com outros docentes do curso, cedidas pelo Centro de Documentação e Memória da Unesp. Muitos desses docentes atuaram como chefes de departamento, coordenadores e vice-coordenadores de curso, vice-diretores e diretores da instituição. Para analisar o perfil dos estudantes, obtivemos da Fundação Vunesp, responsável pelo vestibular da Unesp, dados sobre o perfil socioeconômico dos alunos de graduação que ingressaram nas modalidades BAC e LIC em um intervalo de 7 $\operatorname{anos}(2004$ a 2010).

Analisamos, ainda, dados sobre a seleção para ingresso na pós-graduação fornecidos pela seção de pós-graduação do IQ e dados do Inventário Profissional da Associação dos Ex-Alunos do IQ. O detalhamento sobre o tratamento analítico desses instrumentos está apresentado nas respectivas seções deste texto, quando interpretamos seus resultados. Esse conjunto de informações é confirmado, ainda, por longas entrevistas realizadas com 27 alunos do curso de LIC em Química, que não serão apresentadas detalhadamente neste texto, mas constituem parte fundamental da pesquisa mais ampla da qual esta análise emerge (Massi, 2013). 


\section{pro.posições}

http://dx.doi.org/10.1590/1980-6248-2017-0089

$e$-ISSN 1980-6248

Esses dados foram analisados de acordo com a perspectiva teórica da Sociologia da Educação, considerando as contribuições de Pierre Bourdieu quanto aos conceitos clássicos de habitus, campo e capital cultural, social, econômico e simbólico, e à revisão do conceito de habitus desenvolvida por Bernard Lahire em relação à noção de disposição. Para Lahire (2004), uma disposição, identificada através de um trabalho interpretativo, aponta os princípios que geram e organizam as práticas sociais (observadas a partir de comportamentos, ações, opiniões etc.). As disposições são constitutivas do habitus quando se apresentam como um conjunto coerente associado a uma classe social, conforme enunciado por Bourdieu. No entanto, para Lahire (2012), nem todos os contextos sociais implicam a existência de um habitus, sendo mais frequente a identificação de disposições. Em nosso contexto de pesquisa, a noção de disposições institucionais parece muito mais adequada do que a de habitus, embora esse termo seja adotado na literatura internacional (Reay, David, \& Ball, 2001; Thomas, 2002). Além disso, as disposições foram propostas por Lahire para análise de trajetórias individuais; portanto, foram adotadas nesse contexto como um uso aproximado ou analógico do conceito.

Para organizar nossa análise sobre a história da instituição, recorremos a conceitos de René Kaës (1997) sobre o desenvolvimento de grupos e instituições, estabelecendo três fases: fase inicial e origens (1961-1973); institucionalização da instituição (1974-1990); fase da maturidade da instituição (1991 até o presente). Kaës destaca ainda a presença de “intermediários" em todas as fases de desenvolvimento de instituições; eles serão responsáveis pela adequação dos problemas encontrados às possibilidades do grupo e por sua superação, reconciliando os elementos em conflito. Existiram vários desafios no momento de criação do curso e, para cada um deles, identificamos os possíveis intermediários encontrados pela instituição. Acreditamos que eles se relacionam de forma mais direta com as disposições institucionais, revelando valores e crenças e promovendo práticas entre os agentes da instituição, selecionadas dentro de um conjunto de soluções possíveis.

\section{História e características do curso de licenciatura em Química}

O curso de Química nas modalidades BAC e LIC foi criado em Araraquara em 1961, inicialmente no Departamento de Química da Faculdade de Filosofia, Ciências e Letras dos antigos Institutos Isolados de Ensino Superior, transformando-se em Instituto de Química da 


\section{pro.posições}

http://dx.doi.org/10.1590/1980-6248-2017-0089

recém-criada Unesp em 1977. Em outra publicação (Massi, 2013), detalhamos todas as fases de desenvolvimento da instituição, destacando suas disposições institucionais. Neste texto, enfocamos e detalhamos mais a situação da LIC, a fim de melhor interpretar os dados sobre a trajetória dos egressos.

O objetivo inicial dos fundadores do curso era a formação de professores de Química sob a alegação de uma grande demanda por profissionais, principalmente no interior do estado de São Paulo. É importante destacar que, apesar dessa proposição formativa, os docentes contratados para atuar no curso tinham experiência de pesquisa em indústria e universidades estrangeiras, sem relação direta com a educação básica. Assim, apesar desse objetivo, observamos, ao longo da história do instituto, uma série de acontecimentos que contribuíram para que ele se transformasse em referência no campo da pesquisa, afastando-se de seu papel de formador de professores por não oferecer a modalidade LIC durante mais de 10 anos.

A relação com a LIC teve vivendas alternadas, em função dos interesses da instituição e das demandas e regulamentações externas. Segundo informações fornecidas pela Seção de Graduação do IQ, o curso foi oferecido em conjunto com a modalidade BAC de 1961 até 1975. Porém, o surgimento da Resolução no 30/74 do Conselho Federal de Educação, determinando a obrigatoriedade do oferecimento de uma LIC Plena em Ciências com habilitação em Química, levou à extinção da possibilidade de oferecimento da LIC em Química, mantendo-se, porém, a oferta do BAC, único curso da instituição a partir de 1978.

O IQ precisou implantar a LIC curta e plena em Ciências por determinação federal, porém, esse curso era contrário aos valores institucionais que prestigiavam uma formação científica aprimorada e disciplinar, mesmo na formação de professores. Assim, embora o pedido de conversão tenha sido aprovado, a oferta da LIC em Ciências foi abandonada, pois essa solução não era institucionalmente satisfatória.

Essa instabilidade (ativação e desativação) do curso de LIC em Ciências ${ }^{3}$ revela uma ambiguidade vivida pela instituição, que percebia uma perda decorrente da falta da LIC, porém não estava satisfeita com a solução proposta pela reitoria. Talvez não seja estranha a essa

\footnotetext{
${ }^{3}$ Segundo depoimento de uma funcionária que atuou muitos anos à frente da Seção Técnica Acadêmica, inclusive em sua direção, o IQ tinha interesse em oferecer o curso de LIC, e a solução encontrada pela Reitoria foi reativar a oferta da LIC em Ciências com habilitação plena específica em Química. A partir de 1986 (Res. Unesp 17/86), os bacharéis poderiam solicitar, mediante aproveitamento de estudos, a obtenção do diploma de licenciado em Ciências, com habilitação plena em Química. Porém, essa alternativa também foi desativada em 1990.
} 


\section{pro.posıções}

http://dx.doi.org/10.1590/1980-6248-2017-0089

$e$-ISSN 1980-6248

ambiguidade a "dívida" contraída pela instituição no momento de sua fundação, pois a formação de professores de Química constituía uma das justificativas fundamentais para o curso.

Na sua terceira fase de desenvolvimento (Massi, 2013), com a revogação da Resolução n 30/1974 em 1991, a instituição aceitou a instalação de um curso de LIC em Química oferecido no período noturno, separado do vestibular do BAC. Desse modo, a LIC não impedia o desenvolvimento da instituição, trazendo, ao contrário, ganhos suplementares ao atender uma demanda principalmente externa pelo oferecimento de cursos no período noturno. A Professora E destaca ainda a criação dessa modalidade em relação às demandas da região por profissionais na área: "a licenciatura absorven bem a demanda reprimida regional de formação de profissionais que trabalhavam durante o dia e queriam fazer Quimica e não tinham onde fazer, pois foi o primeiro curso noturno da região na área de Química".

Esse perfil foi característico das primeiras turmas e, posteriormente, sofreu alterações, como destaca o Professor C. Segundo alguns depoimentos, defendia-se a criação de um curso de Bacharelado em Química Tecnológica (BQT) no período noturno, que não se concretizou. Aparentemente, a justificativa foi a falta de funcionários e de infraestrutura de laboratórios, bem como a alta carga horária do curso de BAC. Porém, os docentes disseram que o verdadeiro problema era a falta de professores interessados em atuar no período noturno. Pelo contrário, a LIC podia contar com um grupo pequeno de docentes de apoio constante, segundo o Professor J.

Diante dessas dificuldades e de um histórico de forte tradição em pesquisa em Química do IQ, que lhe garantiu um espaço de legitimidade no campo científico, o currículo do curso de LIC criado em 1991 permite que o formado atue na indústria, pois o Conselho Regional de Química (CRQ) lhe confere as mesmas atribuições do bacharel. Vários docentes identificam esse como um dos motivos pelos quais os licenciados atuam em vários campos depois de formados.

$\mathrm{Na}$ fase atual da instituição, o grande desenvolvimento da pesquisa em Química e de projetos de extensão também contribui para que o encaminhamento profissional dos licenciados não seja voltado prioritariamente para a docência no Ensino Médio. Apesar de várias reformulações curriculares vivenciadas ao longo de sua história, o curso de LIC mantém suas características essenciais: é oferecido em período noturno, separado do vestibular do BAC 


\section{pro.posições}

http://dx.doi.org/10.1590/1980-6248-2017-0089

\section{$e$-ISSN 1980-6248}

(exigindo que o aluno preste novo exame caso queira usufruir das duas habilitações) e recebe as mesmas atribuições que o BAC no CRQ (possibilitando a atuação na indústria).

\section{Atividades de pesquisa e extensão}

Ao longo das fases de desenvolvimento da instituição, podemos observar a presença de intermediários que permitiram a superação de desafios, entre os quais um dos mais fortes e mais atualizados foi a pesquisa. Desde a primeira fase, um diferencial do curso de Química era a exigência da apresentação de uma monografia para a conclusão do curso de BAC e de LIC. Essa medida, além de melhorar o ensino, foi grande incentivadora do desenvolvimento de pesquisas no Departamento de Química. Inicialmente, não havia laboratórios em condições adequadas para que os alunos desenvolvessem pesquisas experimentais.

Uma possível solução para a realização das monografias poderia ter sido o desenvolvimento da pesquisa em Ensino de Química, pois isso era previsto no regulamento. Entretanto, não encontramos registros ou depoimentos que apontem a realização de pesquisas dessa natureza. Graças à existência da coleção Chemical abstracts na biblioteca, optou-se pela realização de levantamentos bibliográficos. Posteriormente, as monografias passaram a ter um caráter mais voltado para a pesquisa experimental em Química, cujas condições para realização estavam sendo alcançadas.

Assim, na primeira fase, o intermediário encontrado pela instituição para imprimir qualidade e diferenciação na formação de profissionais foi a pesquisa em Química. Mesmo incipiente, ela parece ter dado condições para o curso oferecer uma formação de qualidade que garantisse competitividade no campo. A forte vinculação à pesquisa em Química parece ser uma disposição institucional marcante que foi atualizada nas outras fases, estando também diretamente ligada à institucionalização do IQ. A primeira pós-graduação da instituição surgiu apenas um ano depois da criação do instituto, sendo uma das mais antigas da Unesp. Atualmente, ela garante o reconhecimento da instituição no campo brasileiro e internacional da Química. Essa forte presença da pesquisa em Química na instituição permite que a participação em projetos de iniciação científica com bolsas da universidade ou de agências de fomento esteja disponível para todos os alunos que tenham interesse, e muitas vezes é realizada ainda no 


\section{pro.posıções}

http://dx.doi.org/10.1590/1980-6248-2017-0089

\section{$e$-ISSN 1980-6248}

primeiro ano. Em alguns casos, os alunos se envolvem em um projeto de pesquisa logo no início da graduação e permanecem no mesmo laboratório até a conclusão do doutorado.

Se a pesquisa em Química constituiu um intermediário constante ao longo da história do IQ, a extensão só foi desenvolvida plenamente a partir da fase de maturidade da instituição, na qual podia atender demandas externas e revisar questões que haviam sido "evitadas" anteriormente (Kaës, 1997). Nesse caso, havia uma demanda da reitoria, e posteriormente da direção do IQ, para que a instituição desenvolvesse projetos de extensão, uma vez que a Unesp tinha essa atividade como um de seus pontos fortes em comparação às outras universidades do estado com melhores condições para desenvolver pesquisas. Além disso, investindo na extensão, o IQ poderia enfrentar um problema vivido desde a criação do curso: a pouca integração com a cidade de Araraquara, em função de ter sido criado por motivação política e por atender a um público majoritariamente externo à cidade. Por fim, os docentes apontaram a extensão como uma estratégia de divulgação para aumentar a relação candidato/vaga do curso e permitir melhor seleção dos alunos ingressantes.

Apesar dessa justificativa, o desenvolvimento da extensão universitária no IQ foi considerado complexo, pois se tratava de uma unidade acadêmica voltada principalmente para a pesquisa em Química. No início da década de 1990, foram criados novos projetos de extensão que, somados aos já existentes, totalizaram mais de 10 grandes projetos que se mantêm até hoje.

Entre as diversas ações extensionistas promovidas pela instituição, podemos identificar o cumprimento de diferentes "funções" no atendimento de necessidades discentes e institucionais. Inicialmente, destacamos projetos diretamente vinculados aos objetivos de atendimento da comunidade externa à instituição e divulgação do IQ, cujo resultado indireto pode ser o recrutamento de "futuros cientistas" interessados no curso de Química: o Curso Unificado do Campus de Araraquara (Cuca - curso pré-vestibular); o Palestras nas Escolas; além de projetos específicos dentro de outros projetos, como o Um dia na Universidade promovido pelo Grupo Programa Especial de Treinamento do Ministério da Ciência e Tecnologia (Grupo PET).

Outros projetos parecem ter surgido na perspectiva de apoio ao ensino de graduação em Química e indiretamente contribuem para a divulgação da Química na comunidade externa ao IQ, como o Programa de Ensino e o Páginas de Química Geral. Visando uma formação mais ampla e completa dos graduandos, encontramos projetos voltados para a formação do profissional da indústria, na perspectiva de experiência em laboratório, como o Centro de Monitoramento e 


\section{pro.posıções}

http://dx.doi.org/10.1590/1980-6248-2017-0089

\section{$e$-ISSN 1980-6248}

Pesquisa e Ensaio da Qualidade de Combustíveis, Biocombustíveis, Petróleo e Derivados e o Laboratório de Solos; voltados para a perspectiva empresarial, como a Química Júnior Projetos e Consultoria; voltados para a formação de professores, como o Centro de Ciências de Araraquara; e, ainda, voltados para uma formação cultural diversificada que, segundo depoimento dos alunos, também serve como "válvula de escape" para a intensa dedicação aos estudos exigida pela graduação, como o Grupo de Teatro Alquimia e o Grupo PET.

Além das disciplinas de graduação, a participação dos licenciandos em projetos de pesquisa (na iniciação científica) e de extensão em Química parece ocupar um papel fundamental na formação dos alunos, tanto pelo envolvimento direto com as atividades, quanto pela formação recebida em sala de aula, permitindo uma real articulação entre as ações de ensino-pesquisa-extensão (Massi \& Villani, 2015). Esses novos momentos e contextos de formação se constituem, ainda, em oportunidades de (re)socialização.

\section{O perfil dos alunos}

Um estudo detalhado e cuidadoso desses resultados foi objeto de outra publicação (Massi \& Villani, 2014). Apresentamos neste artigo apenas os resultados que se voltam diretamente para as nossas questões de pesquisa.

Analisamos as respostas do questionário socioeconômico da Vunesp referentes ao intervalo de 2004 a 2010, de 2.098 inscritos e 194 matriculados no curso de LIC em Química, que oferece anualmente 30 vagas, e de 5.822 inscritos e 355 matriculados no curso de BAC em Química, que oferece anualmente 50 vagas. Selecionamos para análise 14 questões diretamente relacionadas à nossa pesquisa: estado civil, gênero, ocupação, origem, idade, nível de instrução do pai e da mãe, ocupação do pai e da mãe, salário mensal familiar, conhecimento de língua estrangeira, tipo de escola fundamental e média cursada, frequência a curso pré-vestibular.

Para avaliar se existe associação entre os grupos (bacharéis e licenciados) e as variáveis (questões), utilizou-se o Teste do Qui-Quadrado com auxílio do software Microsoft Excel. Considerou-se, em todos os testes, o nível de significância de 5\%. Utilizou-se o valor p para verificar diferenças estatisticamente significantes $(p<0,05)$. Destacamos que apenas as variáveis "estado civil" e "gênero" não apresentaram diferenças significativas, ou seja, não representam uma diferença no perfil dos bacharéis e licenciados, enquanto todas as outras questões apontam associações entre as variáveis e os grupos. Resumimos alguns desses dados na Tabela 1. 


\section{pro.posıções}

Tabela 1 - Questões e médias porcentuais das respostas dos inscritos e dos matriculados nos cursos de BAC e de LIC em Química

\begin{tabular}{|c|c|c|c|c|c|}
\hline \multirow{2}{*}{ Questões } & \multirow{2}{*}{ Respostas } & \multicolumn{2}{|c|}{ Bacharelado } & \multicolumn{2}{|c|}{ Licenciatura } \\
\hline & & Mat $\%$ & Ins $\%$ & Mat $\%$ & Ins $\%$ \\
\hline \multirow[t]{2}{*}{ Ocupação } & Não trabalha & 92,4 & 83,4 & 70,2 & 62,0 \\
\hline & $\begin{array}{l}\text { Trabalha em tempo parcial ou } \\
\text { integral }\end{array}$ & 3,7 & 11,9 & 23,4 & 32,0 \\
\hline \multirow[t]{2}{*}{ Origem } & Interior de São Paulo & 74,4 & 72,5 & 92,0 & 82,5 \\
\hline & Área metropolitana de São Paulo & 19,2 & 20,3 & 4,4 & 12,2 \\
\hline \multirow[t]{3}{*}{ Idade } & 18 anos ou menos & 62,9 & 67,0 & 34,2 & 59,2 \\
\hline & 19 ou 20 anos & 27,6 & 22,5 & 33,8 & 17,9 \\
\hline & 21 anos ou mais & 7,1 & 8,7 & 31,5 & 21,5 \\
\hline \multirow[t]{2}{*}{$\begin{array}{l}\text { Nível de instrução } \\
\text { do pai }\end{array}$} & $\begin{array}{l}\text { Ensino fundamental (completo ou } \\
\text { incompleto) }\end{array}$ & 18,6 & 28,1 & 41,3 & 51,9 \\
\hline & Ensino médio ou nível superior & 78,7 & 68,9 & 56,9 & 43,6 \\
\hline \multirow[t]{2}{*}{$\begin{array}{l}\text { Nível de instrução } \\
\text { da mãe }\end{array}$} & $\begin{array}{l}\text { Ensino fundamental (completo ou } \\
\text { incompleto) }\end{array}$ & 16,4 & 27,2 & 38,2 & 51,4 \\
\hline & Ensino médio ou nível superior & 82,8 & 71,1 & 59,9 & 44,5 \\
\hline \multirow{3}{*}{ Ocupação da mãe } & Não trabalha & 33,5 & 36,6 & 42,2 & 45,5 \\
\hline & Trabalho sem qualificação & 5,1 & 11,5 & 18,7 & 25,2 \\
\hline & $\begin{array}{l}\text { Profissional liberal, professor ou } \\
\text { técnico }\end{array}$ & 49,0 & 35,7 & 29,4 & 20,8 \\
\hline \multirow[t]{3}{*}{ Ocupação do pai } & Não trabalha & 4,5 & 5,5 & 2,7 & 8,2 \\
\hline & Trabalho sem qualificação & 8,5 & 18,5 & 28,9 & 41,6 \\
\hline & $\begin{array}{l}\text { Profissional liberal, professor ou } \\
\text { técnico }\end{array}$ & 51,8 & 43,2 & 46,3 & 30,1 \\
\hline \multirow{4}{*}{$\begin{array}{l}\text { Salário mensal } \\
\text { familiar }\end{array}$} & Menor que 1,9 salários mínimos & 1,7 & 8,9 & 8,0 & 19,1 \\
\hline & 2 a 4,9 salários mínimos & 24,2 & 34,4 & 45,8 & 52,9 \\
\hline & 5 a 9,9 salários mínimos & 36,0 & 30,0 & 31,1 & 19,8 \\
\hline & Mais de 10 salários mínimos & 37,2 & 25,1 & 14,1 & 6,9 \\
\hline \multirow{2}{*}{$\begin{array}{l}\text { Tipo de escola } \\
\text { fundamental }\end{array}$} & Ensino fundamental público & 27,3 & 47,5 & 60,9 & 79,9 \\
\hline & Ensino fundamental privado & 50,7 & 34,1 & 21,3 & 9,0 \\
\hline \multirow{2}{*}{$\begin{array}{l}\text { Tipo de escola } \\
\text { média }\end{array}$} & Ensino médio público & 14,4 & 38,7 & 44,0 & 74 \\
\hline & Ensino médio privado & 79,4 & 52,8 & 45,8 & 17,6 \\
\hline \multirow{3}{*}{$\begin{array}{l}\text { Cursinho } \\
\text { pré-vestibular }\end{array}$} & Nunca fez & 30,1 & 43,0 & 20,8 & 53,8 \\
\hline & Fez menos de 1 ano & 8,2 & 13,0 & 8,4 & 12,6 \\
\hline & Fez durante 1 ano ou mais & 59,7 & 42,1 & 69,8 & 31,7 \\
\hline
\end{tabular}

Mat: matriculados; Ins: inscritos.

Fonte: adaptado de dados da Fundação Vunesp (2004-2010).

Considerando principalmente o capital econômico e o contexto nacional nesse momento histórico, sem aprofundar a ampla e polêmica discussão sobre a estratificação social nacional, inicialmente observamos a presença de três classes sociais ${ }^{4}$ nesse conjunto de dados:

\footnotetext{
${ }^{4}$ Sabemos que essa classificação pode ser objeto de discussão por se basear unicamente na renda e desconsiderar uma ampla produção sociológica nacional sobre a estratificação de classe (por exemplo, a de Jesse de Souza e Celi
} 


\section{pro.posıções}

http://dx.doi.org/10.1590/1980-6248-2017-0089

os inscritos na LIC apresentam um perfil característico das camadas populares; os matriculados na LIC (portanto, aprovados no vestibular) e inscritos no BAC apresentam um perfil mais próximo à baixa e média classe média; os matriculados no BAC apresentam características das elites.

Assim, existe uma clara diferença de classe entre os alunos da camada média que estão matriculados na LIC e os alunos das elites matriculados no BAC. A identificação desses três grupos aponta, por um lado, a causalidade do provável enunciada por Bourdieu (1998). Os alunos da camada popular nem sequer prestam o vestibular para o BAC, pois não vislumbram essa carreira como possível para seu grupo social. Por outro lado, há uma grande proximidade entre o perfil dos inscritos no vestibular do BAC e os matriculados na LIC, com exceção das variáveis "idade" e "frequência a cursinhos". Isso sugere que os alunos prestaram inicialmente o BAC e, diante da reprovação, fizeram curso pré-vestibular, candidatando-se, no ano seguinte, ao vestibular do curso de LIC, no qual conseguiram aprovação.

Os depoimentos dos alunos confirmam esse dado estatístico: muitos inscritos na LIC preferiam cursar o BAC e só desistiram dessa modalidade em função da não aprovação no vestibular. Assim, 9 alunos dentre 27 entrevistados afirmaram que só prestaram LIC porque o curso era menos concorrido e acrescentaram outras justificativas para essa escolha, como o fato de a LIC ter as mesmas atribuições do BAC pelo CRQ, ou de o aluno ter o dia livre para fazer estágios. Além desses, outros 4 alunos disseram ter escolhido a LIC "sem querer", em função de um erro na hora de preencher a ficha de inscrição. Possivelmente, esse tipo de erro está associado ao receio de não obter aprovação no curso de BAC, mas poder consegui-la na LIC, como observamos em vários casos. Segundo a Professora M, esse é o novo perfil dos alunos da licenciatura: "começon a vir uma maioria que não queria dar aula, faz̧ia a licenciatura porque era mais fácil

Scalon). Um rigor metodológico exigiria a adoção da definição bourdiana, apresentada na obra $A$ distinção (Bourdieu, 2007), de que cada estudo desse tipo exigiria "construir a classe objetiva, como conjunto de agentes situados em condições homogêneas de existência, impondo condicionamentos homogêneos e produzindo sistemas de disposições homogêneas, próprias a engendrar práticas semelhantes, além de possuir um conjunto de propriedades comuns" (p. 97). Porém, diante do objetivo da discussão e dos dados disponíveis, adotamos como referência a renda per capita desses estudantes, que é usada como parâmetro para a Secretaria de Assuntos Estratégicos do Governo Federal para definir as classes sociais no período em que esses dados foram coletados de acordo com a seguinte escala: extremamente pobres, até $\mathrm{R} \$ 81$; pobres, entre $\mathrm{R} \$ 81$ e $\mathrm{R} \$ 162$; vulneráveis, entre $\mathrm{R} \$ 162$ e $\mathrm{R} \$ 291$; baixa classe média, entre $\mathrm{R} \$ 291$ e $\mathrm{R} \$ 441$; média classe média, entre $\mathrm{R} \$ 441$ e $\mathrm{R} \$ 641$; alta classe média, entre $R \$ 641$ e $R \$ 1.019$; baixa classe alta, entre $R \$ 1.091$ e $R \$ 2.480$; e alta classe alta, a partir de $R \$ 2.480$. Assim, classificamos os grupos de alunos com base na questão da Vunesp sobre a faixa salarial familiar e em outra questão, não apresentada neste trabalho, sobre o número de membros que viviam desta renda familiar, cuja resposta majoritária de todos os grupos (45\% dos inscritos e $52 \%$ dos matriculados no BAC; e $42 \%$ dos inscritos e dos matriculados na LIC) foi de quatro integrantes. 


\section{pro.posições}

http://dx.doi.org/10.1590/1980-6248-2017-0089

$e$-ISSN 1980-6248

entrar, era de noite, raros queriam dar aula - três ou quatro em uma turma de 30. Tem uns que querem dar aula, mas na universidade".

Comparando apenas os matriculados nos dois cursos, identificamos, com valores consideráveis de diferenças porcentuais, maior quantidade de alunos da LIC, em relação aos do BAC, que têm 21 anos ou mais (31,5\% vs. $7 \%$ ), cujos pais (41,3\% vs. 18,6\%) e mães (38,2\% vs. 16,4\%) têm escolaridade em nível fundamental (completo ou incompleto) e se dedicam a ocupações sem qualificação ( $28,9 \%$ vs. $8,5 \%)$; cujas famílias têm renda mensal de 2 a 4,9 salários mínimos (45,8\% vs. $24,2 \%)$; e que cursaram o ensino fundamental (60,9\% vs. $27,3 \%$ ) e ensino médio (44\% vs. 14,4\%) em escola pública.

Apesar desse perfil menos favorecido, destacamos que os matriculados na LIC são oriundos das camadas médias - mesmo que de frações mais baixas. Com isso, $70 \%$ dos alunos não trabalham, pois não precisam colaborar com a renda familiar. Além disso, em função de suas cidades de origem ( $92 \%$ no interior de São Paulo), a maioria dos alunos muda-se para a cidade de Araraquara para se dedicar ao curso, mas frequenta-o no período noturno, tendo grande disponibilidade para se envolver nas atividades extracurriculares oferecidas pela graduação.

\section{A conjugação dos fatores analisados: perfil dos alunos e características do curso de licenciatura}

A conjugação do perfil do licenciando e das características do curso favorece a participação desses alunos em projetos de pesquisa e extensão. Destacamos nos depoimentos dos docentes a importância e o papel da extensão para a formação. Segundo o Professor G, " $a$ extensão traz a comunidade para o ambiente universitário, leva um pouquinho o pesquisador, estudante para a realidade de uma comunidade", fazendo com que os egressos do curso saiam "com o pé no chão" em relação ao mercado. Para a Funcionária N, a maioria dos alunos apresenta um grande envolvimento nos projetos, o que culmina em "mudança de comportamento ..., comprometimento, consciência, cidadania, enfim, da importância da universidade para a sociedade". A Professora M acrescenta que as disciplinas pedagógicas e o tempo que os licenciandos têm para estudar e fazer estágio propiciam um amadurecimento na comunicação e fazem com que eles tenham "uma capacidade de pensar, argumentar, melhor do que o bacharelado .... O bacharel fica 8 horas por dia na sala de aula, como vocêpensa? Como você raciocina?". 


\section{pro.posıções}

http://dx.doi.org/10.1590/1980-6248-2017-0089

$e$-ISSN 1980-6248

A partir dos depoimentos dos alunos da LIC entrevistados e algumas consultas aos do BAC, nos parece que o interesse pela pesquisa em Química é maior por parte dos licenciandos. Para os bacharéis, a motivação para atuação na indústria é mais forte, sendo a pós-graduação vista como possibilidade apenas em momentos de pouca oferta de emprego na indústria. Além disso, os alunos da LIC são preferidos pelos professores por terem mais tempo para se dedicar à pesquisa nos laboratórios de Química, como destacado pelo Professor C: "alunos do bacharelado que trabalharam comigo na pesquisa ficavam muito bravos, pois diriam que estavam sendo prejudicados pela licenciatura porque os professores preferiam esses alunos para desenvolver pesquisa, pela disponibilidade de horário".

Em alguns depoimentos, percebemos que os projetos de extensão pareciam até compensar deficiências de formação acadêmica, como a baixa articulação do curso de LIC com a formação de professores, num contexto de forte valorização e investimento na pesquisa em Química (Massi \& Villani, 2015). Nesse sentido, alguns projetos contrariam a tendência geral da instituição de formação do licenciado para a pesquisa em Química e para a indústria, oferecendo um contato direto com a prática docente e permitindo uma visão mais positiva desta atividade.

Essa percepção é confirmada pelas entrevistas realizadas com os alunos. Segundo o Professor C, "foi um sonbo, quando a licenciatura foi criada, de que ela formaria professores, mas quem acabou cumprindo esse papel foi mais o Cuca do que a licenciatura em Quimica". Em nossa interpretação, essa contradição permitiria à instituição manter o discurso de apoio à formação de professores sem modificar seu currículo nem reduzir a participação dos licenciandos nos laboratórios de pesquisas em Química.

\section{A modificação do destino social mais provável dos licenciados}

Nesta seção, pretendemos demonstrar, com base em um significativo volume de dados longitudinais sobre os egressos da Unesp, que os licenciados têm oportunidades de ampliar seu destino profissional, geralmente menos privilegiado no Brasil, em relação aos bacharéis. Essa argumentação se sustenta em duas hipóteses principais que serão desenvolvidas nesta seção: (i) quanto à formação científica recebida, não existem diferenças entre a LIC e o BAC, pois os egressos dos dois cursos têm a mesma oportunidade de ingresso na pós-graduação em Química; (ii) quanto à inserção profissional, o licenciado pode escolher quase equitativamente entre a 


\section{pro.posıções}

http://dx.doi.org/10.1590/1980-6248-2017-0089

$e$-ISSN 1980-6248

indústria, o ensino e a pós-graduação em Química, enquanto o bacharel não tem habilitação para o magistério e procura principalmente a pós-graduação e a indústria, alternando essas opções em função da disponibilidade do mercado.

Para analisar o primeiro aspecto - a qualidade da formação em Química oferecida pelos cursos -, nos pautamos em dados fornecidos pela Seção de Pós-Graduação do IQ e coletados no sistema de Currículo Lates do Conselho Nacional de Desenvolvimento Científico e Tecnológico (CNPq). Analisamos o resultado da seleção de mestrado do IQ entre 2004 e 2010, que ocorre duas vezes por ano aprovando, no máximo, 15 alunos por seleção. Em dois semestres analisados foram aprovados menos de 15 alunos, portanto, analisamos um total de 201 ingressantes do período. Observando a origem desses 201, alunos selecionamos apenas os egressos do IQ, que totalizam 68 egressos do BAC e BQT e 33 egressos da LIC; os outros 100 ingressantes são oriundos de outras instituições. O processo seletivo consiste em prova dissertativa sobre conteúdos químicos e análise do currículo dos candidatos. Nosso objetivo era observar as chances de ingresso que os alunos da LIC tinham em comparação aos alunos do BAC e BQT do IQ. Os alunos do BQT ingressam no vestibular do BAC e escolhem essa modalidade a partir da metade do curso, portanto, estão incluídos na categoria BAC. Além disso, esse curso é o que mais se afasta da LIC, pois representa uma opção para parte dos BAC, que nem sempre é mais atrativa, apenas mais específica para a atuação na indústria. Os poucos casos de mudança de curso (exclusivamente através de participação em novo vestibular) e de interesse indicado pelos alunos se restringem ao BAC e BQT, sem nenhum intercâmbio com a LIC.

Considerando a diferença proporcional de formandos nos dois cursos - 50 formandos no BQ e BQT e 30 formandos na LIC -, os alunos da LIC têm uma inserção considerável na seleção do mestrado da instituição. Partindo dos 201 ingressantes do mestrado, eles representam 16,4\% dos aprovados em comparação a 33,8\% de alunos oriundos do BQ e BQT, o que comprova os depoimentos dos docentes e a impressão dos alunos sobre a formação em Química de qualidade e o desenvolvimento de atividades extracurriculares que melhorem o currículo dos discentes.

Calculando o mesmo dado de outra forma, continua evidente a igualdade de oportunidades no processo seletivo da pós-graduação. Considerando a quantidade média de formandos entre 2004 e 2010 da LIC e do BAC, os aprovados no mestrado representam 15,7\% (33/210) dos egressos da LIC e 19,4\% (68/350) dos egressos do BAC. É importante lembrar, 


\section{pro.posições}

http://dx.doi.org/10.1590/1980-6248-2017-0089

\section{$e$-ISSN 1980-6248}

ainda, que muitos alunos seguem os estudos de pós-graduação em Química em outros programas além da pós-graduação do IQ/Unesp, e que as vagas desse programa também são preenchidas por alunos de outras instituições do Brasil.

Para analisar a inserção profissional dos egressos, obtivemos acesso ao Inventário Profissional disponibilizado pela Associação dos Ex-Alunos do IQ. O Inventário é produzido através de envio de questionários on-line para os ex-alunos, que o atualizam ao longo do tempo com informações sobre sua inserção profissional. $\mathrm{O}$ acesso a diferentes versões dessa publicação permitiu observar as mudanças no preenchimento das informações por parte dos egressos que evidenciam o caráter longitudinal deste dado. $\mathrm{O}$ acesso ao Currículo Lattes de alguns dos egressos também evidenciou a veracidade das informações fornecidas.

Apesar disso, entendemos que não existe um controle preciso, por parte da Associação, quanto às datas de atualização e quanto ao tipo de informação fornecida, logo, restringimos a análise para o período de 1995, formatura das primeiras turmas de LIC, até 2004, ano em que a quantidade de respostas ainda era considerável ${ }^{5}$. A partir desses dados, realizamos a contagem de egressos que se encaminharam profissionalmente para a indústria, a docência e a pesquisa, incluindo empresários na docência e na indústria. Na pesquisa, incluímos apenas os que desenvolvem essa atividade profissionalmente em universidades e instituições de pesquisa; contamos também quantos fizeram estudos de pós-graduação em nível de mestrado, doutorado e pós-doutorado em Química.

Apresentamos os resultados dessa análise na Tabela 2. Nela, além da LIC e BAC, apontamos os resultados referentes aos egressos do BQT, mas neste trabalho, diante do objetivo da discussão, realizamos as discussões sobre as duas modalidades em conjunto. Consideramos apenas os dados dos egressos que forneceram informações ao inventário, mesmo que parcial como só a formação acadêmica - e que não mudaram seu ramo de atuação: 206 egressos do BAC, 147 do BQT e 136 da LIC. Uma quantidade pequena dos egressos atuava em dois ramos simultaneamente: a indústria e a docência. Diante disso, para analisar e comparar os encaminhamentos e a formação, calculamos as porcentagens, indicadas na Tabela 2 , do total de respondentes indicados acima.

\footnotetext{
${ }^{5}$ Apesar de destacarmos essas fragilidades de nossa fonte de informações, acreditamos que esses resultados ainda são importantes indícios sobre o destino dos egressos dessa instituição.
} 


\section{pro.posıções}

http://dx.doi.org/10.1590/1980-6248-2017-0089

\section{$e$-ISSN 1980-6248}

Tabela 2 - Encaminhamento profissional e formação acadêmica dos egressos do IQ da Unesp de 1995 a 2004

\begin{tabular}{|c|c|c|c|c|c|c|}
\cline { 2 - 7 } \multicolumn{1}{c|}{} & \multicolumn{2}{c|}{ Encaminhamento profissional } & \multicolumn{3}{c|}{ Formação acadêmica } \\
\hline Egressos & Indústria & Docência & Pesquisa & Mestrado & Doutorado & Pós-doutorado \\
\hline BAC & 63 & 25 & 16 & 154 & 84 & 18 \\
$(206)$ & $(30,6 \%)$ & $(12,1 \%)$ & $(7,8 \%)$ & $(74,8 \%)$ & $(40,8 \%)$ & $(8,7 \%)$ \\
\hline BQT & 68 & 11 & 6 & 84 & 42 & 7 \\
$(147)$ & $(46,3 \%)$ & $(7,5 \%)$ & $(3,4 \%)$ & $(55,6 \%)$ & $(28,6 \%)$ & $(4,8 \%)$ \\
\hline LIC & 32 & 46 & 8 & 60 & 40 & 6 \\
$(136)$ & $(23,5 \%)$ & $(33,8 \%)$ & $(5,9 \%)$ & $(44,1 \%)$ & $(29,4 \%)$ & $(4,4 \%)$ \\
\hline
\end{tabular}

Fonte: adaptado de dados da Associação dos Ex-Alunos do IQ (1995-2004).

Quanto ao encaminhamento profissional, os resultados mostram que a opção pela pesquisa, ou seja, pela carreira acadêmica na universidade, principalmente, é minoria entre os egressos de todas as modalidades. Os egressos do BQT, cuja formação é específica para a indústria, se encaminham de modo mais significativo para essa área (46,3\%). Os egressos da LIC optam, em proporções bastante próximas, entre a docência $(33,8 \%)$ e a indústria $(23,5 \%)$. Já os egressos do BAC se encaminham mais para a indústria $(30,6 \%)$ do que para a docência $(12,1 \%)$, embora a opção pelo ensino ainda apareça em maior proporção do que nos egressos do BQT.

Entendemos que esses dados apontam vantagens (ou, ao menos, semelhanças) dos egressos da LIC, oriundos da baixa e média classe média, em relação aos do BAC, oriundos das camadas altas: (i) eles têm maior diversidade de escolhas em relação ao BAC por apresentarem proporções relativamente próximas de encaminhamento para a indústria e para o ensino, além de os bacharéis não terem a certificação que os habilita à docência em condições estáveis na rede pública (exceto para o nível superior, quando o edital considera essa possibilidade, ou se reingressar em um curso de licenciatura); (ii) eles também não parecem sofrer grandes desvantagens em relação aos egressos do BAC ao optar pela indústria em vez da docência, uma vez que a quantidade de bacharéis na indústria é maior do que a de licenciados em apenas 7\%, o que nos parece muito distante de uma exclusão dessa opção de encaminhamento profissional; (iii) o encaminhamento para a carreira universitária dos licenciandos é maior do que o dos bacharéis, o que merece destaque, já que, tradicionalmente, essa opção era restrita à elite brasileira - como mostrado por Hey (2008) quanto à área de educação superior - e permanece como uma opção de relativo prestígio social. 


\section{pro.posıções}

http://dx.doi.org/10.1590/1980-6248-2017-0089

\section{$e$-ISSN 1980-6248}

Quanto à formação em nível de pós-graduação, destacamos um grande encaminhamento nas três modalidades (74,8\% no BAC, 55,6\% no BQT e 44,1\% na LIC), reforçando o importante papel que a pesquisa assume nessa instituição. A quantidade significativa de bacharéis $(74,8 \%)$ que se encaminham para o mestrado é quase a metade em relação ao doutorado $(40,8 \%)$ e diminui de maneira drástica quando observamos a porcentagem de egressos que segue atuando profissionalmente na pesquisa acadêmica $(7,8 \%)$. Esse dado nos parece coerente com a indicação dos docentes de que essa continuidade nos estudos é vista como alternativa ao encaminhamento na indústria em momentos de pouca oferta de emprego. Isso não parece acontecer com os egressos da LIC e do BQT, que procuram o mestrado em proporções relativamente próximas (55,6\% e 44,1\%, respectivamente).

Além disso, demonstramos que a menor quantidade de egressos da LIC que cursa mestrado em relação aos do BAC não se justifica pela incapacidade dos licenciados de serem aprovados no processo seletivo, podendo, portanto, indicar maior possibilidade de atuação no mercado que não os leva a considerar a pós-graduação como opção.

Assim, entendemos que esse conjunto de dados aponta diretamente a existência das mesmas probabilidades objetivas de inserção acadêmica e profissional dos egressos da LIC e do BAC, com base em duas constatações: (i) diante do processo seletivo de ingresso na pós-graduação em Química do IQ/Unesp, os egressos do BAC e da LIC têm as mesmas chances de inserção; (ii) diante do encaminhamento profissional, os egressos da LIC têm maior diversidade de escolhas profissionais e praticamente as mesmas chances de inserção que os do BAC. Esse dado representa uma modificação do destino social dos licenciandos de origem social menos favorecida do que dos bacharéis que, tendencialmente, teriam oportunidades de inserção menos legítimas ao concluir o curso de LIC em relação aos egressos do BAC, como apontado pela "teoria da reprodução" no plano macrossociológico.

Se, por um lado, essa modificação é positiva quanto à ascensão social dos egressos em relação a encaminhamentos profissionais considerados mais prestigiados, não podemos nos furtar de constatar uma relação contraditória quanto aos objetivos formativos do curso: observa-se em todas as esferas de análise uma total desvalorização e desvio de um projeto de formação de professores.

Analisando os dados sobre a inserção profissional desses alunos, com base no Inventário Profissional disponibilizado pela Associação dos Ex-Alunos do IQ, percebemos que apenas 


\section{pro.posıções}

http://dx.doi.org/10.1590/1980-6248-2017-0089

$e$-ISSN 1980-6248

$33,8 \%$ se encaminham para a docência. Segundo os depoimentos dos alunos, as atividades de extensão ligadas à divulgação científica e ao ensino de Química parecem ser as principais responsáveis por esse encaminhamento. Essas atividades assumiram a função de fornecer aos licenciandos uma perspectiva profissional durante a graduação, reduzindo seu desconforto com um currículo e um ensino oficial, muitas vezes distante de suas capacidades e seus entendimentos (Massi \& Villani, 2015). Assim, as críticas ao ensino de Química, apresentado na estrutura curricular de forma distanciada da realidade, parecem ser compensadas pelo envolvimento em atividades que aproximam os alunos da educação básica. Além disso, a necessária participação dos licenciandos no projeto institucional voltado para a pesquisa em Química reduziu fortemente sua discriminação por parte dos docentes, devido ao limitado capital cultural que possuíam ao ingressar na instituição.

\section{Considerações finais}

No IQ, a LIC foi implantada como forma de "pagar a dívida" com suas origens e oferecer uma opção de relativa "segunda categoria" para formação de um perfil diferenciado do BAC: alunos que não poderiam estudar em período integral, mas que deveriam receber uma formação sólida em Química, seguindo os princípios da instituição. No entanto, um conjunto de circunstâncias modificou esse projeto, tornando a "opção dos mais pobres" uma estrada para o sucesso profissional e o avanço social dos licenciandos. Esta modificação aconteceu por uma série de encontros e desencontros, pressões institucionais e políticas, iniciativas institucionais e de alunos.

Os depoimentos sobre a criação da LIC apontam a existência de um "lobby do bacharelado" que cuidava de sua valorização interna e externa e tinha como resultado efetivo um currículo extremamente carregado de conteúdo de Química. Como consequência, os alunos tinham pouco espaço para investir na sua formação, que ficava cada vez mais engessada. Por outro lado, o curso de LIC, por ser oferecido à noite e não carregar o peso do título de "bacharel", permitia uma carga mais leve, porém com a mesma qualidade. Por sua vez, os licenciandos, desde o primeiro ano do curso, podiam obter bolsas de extensão e pesquisa em Química na instituição, não precisando trabalhar para se manter na universidade. As pressões políticas, que queriam a atuação do IQ na promoção do bem-estar local, e as estratégias institucionais da Unesp, que queria se destacar no contexto das universidades públicas paulistas, garantiam a abundância e a continuidade das bolsas, inclusive para projetos de extensão. Assim, 


\section{pro.posições}

http://dx.doi.org/10.1590/1980-6248-2017-0089

\section{$e$-ISSN 1980-6248}

os licenciandos, que faziam o curso noturno, podiam desfrutar do dia livre para trabalhar em projetos que ofereciam uma grande quantidade e variedade de oportunidades, complementando sua formação (formal e informal) e permitindo um melhor ajuste às necessidades individuais.

Considerando, ainda, que existem múltiplas formas de transmitir capital cultural e que, na realidade, esse é o capital transmitido ao participar dessas atividades múltiplas, os licenciados teriam a oportunidade de reconverter sua formação, inicialmente mais pobre em termos de capital cultural. É importante notar que, para o IQ, o conjunto dos projetos de pesquisa em Química e extensão constituía o núcleo central de seu "marketing institucional" para se destacar no cenário estadual, nacional e internacional, ao passo que, para os licenciandos, constituía o núcleo de sua formação mais aprimorada e potencializadora, capaz de reverter o handicap inicial em relação aos bacharéis. Esse quadro não alterava a formação e valorização simbólica do BAC, porém, permitia ao licenciando chances concretas de inserção na pós-graduação e no mercado de trabalho, visto sob uma perspectiva mais ampla de atuação, concretizando uma ampliação e valorização de seu destino social mais provável.

As disposições institucionais, marcadas pela valorização quase absoluta da pesquisa acadêmica e pela ausência de uma reflexão educacional mais aprofundada sobre as reais necessidades e possibilidades de bacharéis e licenciados, dificultam a tomada de decisões que envolvam um investimento mais aprimorado no ensino, revelando a ambiguidade desse processo singular. $\mathrm{O}$ fato de licenciados e bacharéis encontrarem facilmente trabalho após a formatura e atenderem às necessidades da pós-graduação em Química da instituição constitui argumento para não investir em mudanças radicais no ensino de graduação e de pós-graduação. No entanto, nossa pesquisa evidencia que esse cenário é resultado de contingências e não de investimentos estruturais, já que, comprovadamente, a instituição oferece uma formação de qualidade a todos - comprovada por exames nacionais governamentais como o Exame Nacional de Desempenho dos Estudantes (Enade), por avaliadores privados como o Guia do Estudante e pela avaliação da pós-graduação pela Coordenação de Aperfeiçoamento de Pessoal de Nível Superior (Capes), que impacta indiretamente na graduação -, permitindo a ampliação das perspectivas profissionais dos egressos da licenciatura sem prejuízo das demais vantagens reveladas na modificação de seu destino social mais provável.

Nesse sentido, para que a estratégia da instituição ultrapasse os objetivos de pesquisa em Química e de marketing e se torne conscientemente potencializadora e capaz de maximizar as perspectivas profissionais de bacharéis e licenciados, nos parece que deveria incluir também a possibilidade de atuar na pesquisa em Educação Química, favorecendo a formação de grupos de pesquisa correspondentes, introduzindo uma opção de iniciação científica em Educação 


\section{pro.posições}

http://dx.doi.org/10.1590/1980-6248-2017-0089

\section{$e$-ISSN 1980-6248}

Química e promovendo pesquisas e ações formativas sobre a própria prática docente vigente na instituição.

A presença na Unesp de um dos melhores programas de pós-graduação na área - o Programa de Educação para a Ciência, lotado em Bauru -, mesmo que em outra cidade (próxima a Araraquara), representa um importante caminho para ampliar ainda mais as perspectivas profissionais dos licenciandos, abrindo-lhes as portas das universidades públicas e particulares, das secretarias de ensino e das organizações educacionais, sem precisar cursar a pós-graduação em outra instituição.

Em nossa interpretação, essa abertura poderia ter como consequência uma atuação mais sistemática do IQ no Ensino da Química, com aprimoramento do currículo oficial de formação dos licenciados (e dos bacharéis). Além disso, seria um grande exemplo para todas as instituições universitárias formadoras de professores de Química de articulação entre pesquisa, ensino e extensão com a participação de docentes e discentes. Evidentemente, não estamos afirmando que o aprimoramento da atuação da instituição na formação inicial de professores resolveria o problema da valorização do professor de Ensino Médio público (e também particular), pois isso depende de outras iniciativas, principalmente do estabelecimento de uma carreira docente e o aumento significativo do seu salário.

\section{Referências}

Bourdieu, P. (1998) Futuro de classe e causalidade do provável. In M. A. Nogueira, \& A. Catani (Eds.), Escritos de educaşão (pp. 83-126). Petrópolis: Vozes.

Bourdieu, P. (2007). A distinção: crítica social do julgamento. São Paulo: Edusp.

Bourdieu, P., \& Passeron, J.-C. (2012). Les héritiers: les étudiants et la culture. Paris: Les Editions de Minuit.

Bourdieu, P., \& Passeron, J.-C. (2014). A reprodução: elementos para uma teoria do sistema de ensino. Petrópolis: Editora Vozes.

Catani, A. M., Catani, D. B., \& Pereira, G. R. M. (2001). As apropriações da obra de Pierre Bourdieu no campo educacional brasileiro, através de periódicos da área. Revista Brasileira de Educação, (17), 63-85. doi:10.1590/S1413-24782001000200006

Dias-da-Silva, M. H. G. F., \& Muzzeti, L. R. (2006). Licenciaturas Light: resultado das lutas concorrenciais no campo universitário? Contexto e Educação, 21(75), 11-28. doi:10.21527/2179-1309.2006.75.11-28 


\section{pro.posições}

http://dx.doi.org/10.1590/1980-6248-2017-0089

\section{$e$-ISSN 1980-6248}

Duru-Bellat, M. (2006). L'inflation scolaire: les désillusions de la méritocratie. Paris: Éditions du Seuil.

Hey, A. P. (2008). Esboço de uma sociologia do campo acadêmico: a educação superior no Brasil. São Carlos/SP: EdUFSCar.

Kaës, R. (1997). O grupo e o sujeito do grupo: elementos para uma teoria psicanalitica do grupo. São Paulo: Casa do Psicólogo.

Lahire, B. (2004). Retratos sociológicos: disposições e variações individuais. Porto Alegre: Artmed.

Lahire, B. (2012). Monde pluriel: penser l'unité des sciences sociales. Paris: Éditions de Seuil.

Massi, L. (2013) Relação aluno-instituição: o caso da licenciatura do Instituto de Química da Unesp/Araraquara. Tese de Doutorado, Universidade de São Paulo, São Paulo.

Massi, L. \& Villani, A. (2014) Contribuições dos estudos de perfil dos graduandos: o caso dos cursos de licenciatura e bacharelado em Química da Unesp/Araraquara. Revista Brasileira de Pesquisa em Educação em Ciências, 14(1), 151-170.

Massi, L. \& Villani, A. (2015) O currículo da formação de professores em um Instituto de Química: encontros e desencontros entre a prescrição e a prática. Investigações em Ensino de Ciências, 20(3), 187-204. doi:10.22600/1518-8795.ienci2016v20n3p187

Nogueira, C. M. M., \& Nogueira, M. A. (2002). A sociologia da educação de Pierre Bourdieu: limites e contribuições. Educaşão \& Sociedade, 23(78), 15-36. doi:10.1590/S010173302002000200003

Reay, D., David, M., \& Ball, S. (2001). Making a difference?: Institutional habituses and higher education choice. Sociological Research Online, 5(4), 14-25. doi:10.5153/sro.548

Thomas, L. (2002). Student retention in higher education: the role of institutional habitus. Journal of Education Policy, 17(4), 423-442. doi:10.1080/02680930210140257

Zucco, C. (2007). Graduação em Química: avaliação, perspectivas e desafios. Química Nova, 30(6), 1429-1434. doi:10.1590/S0100-40422007000600010

Yin, R. K. (1989). Case study research: design and methods. Newbury Park: Sage Publications.

Submetido à avaliação em 03 de maio de 2017; revisado em 22 de novembro de 2018; aceito para publicação em 27 de fevereiro de 2019. 